\title{
Decreased $\beta$-cell proliferation impairs the adaptation to pregnancy in rats malnourished during perinatal life
}

\author{
I Avril, B Blondeau, B Duchene, P Czernichow and B Bréant \\ Institut National de la Santé et de la Recherche Médicale Unité 457, Hôpital Robert Debré, 48 Boulevard Sérurier, 75019 Paris, France \\ (Requests for offprints should be addressed to B Breant; Email: breant@idf.inserm.fr)
}

\begin{abstract}
We investigated the cellular mechanisms responsible for the inability of 8 -month-old previously malnourished (PM) females to adapt their $\beta$-cell mass during pregnancy. The evolution during pregnancy of $\beta$-cell fraction, size and proliferation was studied. At day 21 of pregnancy $\beta$-cell fraction increased less in PM than in control females, compared with their non-pregnant values. A slight $\beta$-cell hypertrophy was observed during pregnancy in both groups. In control females, $\beta$-cell 5-bromo-2'deoxyuridine (BrdU) labelling index (LI) increased from $0 \cdot 07 \pm 0 \cdot 04 \%$ before pregnancy to $1 \cdot 13 \pm 0 \cdot 20 \%$ at day 12 and decreased thereafter to reach again basal levels at day 21. In PM females, $\beta$-cell proliferation rate was decreased at day $12(0 \cdot 74 \pm 0 \cdot 15 \%, P<0 \cdot 05)$ but similar to controls at all other stages studied. Separate analysis of the head and
\end{abstract}

tail parts of the pancreas in control animals revealed that the $\beta$-cell fraction during pregnancy increased more in the head than in the tail; similarly, BrdU LI increased 20-fold in the head and 10-fold in the tail, compared with non-pregnant values. In PM females, no adaptation of $\beta$-cell fraction could be observed in the head, where BrdU LI was decreased by half at day 12 of pregnancy. In PM females the lactogenic activity was twice that of controls at day 12 whereas all $\beta$-cells expressed the prolactin receptor. In conclusion, perinatal malnutrition impairs subsequent adaptation to pregnancy by decreasing $\beta$-cell proliferation in the head of the pancreas at a critical time during pregnancy.

Journal of Endocrinology (2002) 174, 215-223

\section{Introduction}

To meet the increased demand for insulin over a prolonged period of time, such as needed during pregnancy, the maternal endocrine pancreas undergoes a number of adaptive functional and structural changes. These changes include increasing insulin synthesis (Bone \& Taylor 1976) and secretion (Parsons et al. 1992), lowering the glucose stimulation threshold (Green \& Taylor 1972), enhancing $\beta$-cell proliferation (Parsons et al. 1992, Kawai \& Kishi 1997, Nieuwenhuizen et al. 1997) and increasing gapjunctional coupling between $\beta$-cells (Sheridan et al. 1988). In particular, these acute and reversible structural changes involve a doubling of $\beta$-cell mass, which has been attributed to $\beta$-cell hyperplasia (Green \& Taylor 1972, Van Assche et al. 1979, Marynissen et al. 1983), and a small contribution of neogenesis has also been suggested (Aerts et al. 1997). In rodents, all these structural adaptations peaking around day 15 of pregnancy have been demonstrated to be controlled by placental lactogens (PLs) which are secreted from day 10 of pregnancy (Parsons et al. 1992, Weinhaus et al. 1996, Kawai \& Kishi 1999).

We have previously shown that maternal general food restriction in late pregnancy induces intra-uterine growth retardation (IUGR) and decreases $\beta$-cell mass in the offspring at birth (Garofano et al. 1997). Moreover, this early malnutrition has long-lasting consequences on glucose homeostasis and further adaptation of the endocrine pancreas to situations of increased insulin demand such as ageing (Garofano et al. 1999) and pregnancy (Blondeau et al. 1999). Although female offspring that have been malnourished during their perinatal life adapt quite normally to pregnancy in young adulthood, older females become unable to increase their islet mass and insulin content during pregnancy (Blondeau et al. 1999).

The aim of the present work was to investigate the mechanisms responsible for this impaired adaptation by studying the cellular processes normally involved in the adaptation of $\beta$-cell mass to pregnancy, namely $\beta$-cell hypertrophy and $\beta$-cell proliferation. To this end, female offspring born with IUGR from food-restricted dams were fed freely from weaning and studied at 8 months of age, before and at various stages of pregnancy, in comparison with age-matched control female offspring. Morphometric measurements of $\beta$-cell fraction, individual $\beta$-cell size and $\beta$-cell proliferation after in vivo 5 -bromo2 -deoxyuridine (BrdU) incorporation were performed on pancreatic sections. As early malnutrition was also shown 
to affect to a greater extent $\beta$-cells from the head part of the pancreas in adult male offspring (Garofano et al. 1998a), a separate analysis of the head and tail parts of the pancreas was also undertaken.

\section{Materials and Methods}

\section{Animals and study design}

This study was conducted on 8-month-old control female rat offspring and female rat offspring born with IUGR, obtained as follows. Wistar rat dams on day 5 of pregnancy (Janvier Breeding Centre, Le Genêt-St-Isle, France) were housed individually and maintained under a $12 \mathrm{~h}(0700$ $1900 \mathrm{~h})$ light: $12 \mathrm{~h}$ darkness cycle and constant temperature $\left(22{ }^{\circ} \mathrm{C}\right)$. All animals were fed a standard laboratory rat chow with free access to tap water. Every pregnant dam was weighed upon its arrival and randomly assigned to the control or food-restricted group. Control pregnant dams were fed freely whereas pregnant dams from the foodrestricted group were fed $50 \%$ of the daily intake of pregnant control dams from day 15 of pregnancy. At parturition, all pups were weighed before suckling and those born from restricted mothers and showing a severe IUGR were selected (body weight $<$ control weight -2 S.D.). Litter size was equalized out to eight. The same rate of maternal food restriction (50\%) was carried on until the end of lactation (Garofano et al. 1998b). From weaning and until the end of the experiment, the offspring from both groups were fed freely. Control and IUGR-born previously malnourished (PM) adult female offspring were studied at 8 months of age before and during pregnancy. They were mated overnight with control male Wistar rats and the day on which vaginal plugs were observed was designated day 0 of pregnancy. Pregnant females from both groups were caged individually and studied at days 12, 14, 17 and 21 of pregnancy, in comparison with non-pregnant females. This laboratory has an agreement for laboratory animal care facilities and experimentation, granted by the French Agricultural Ministry (authorization \#7612).

\section{Tissue processing}

The animals (four or five per group and stage of pregnancy) were i.p. injected with a dose of $50 \mu \mathrm{g} / \mathrm{g}$ body weight of BrdU (Sigma, Saint Quentin Fallavier, France) $1 \mathrm{~h}$ before killing, which was done by i.p. injection of pentobarbital. The whole pancreas was excised and two pieces of approximately $200 \mathrm{mg}$ located in the head (duodenal part) and the tail (spleen part) were separately fixed in a $3.7 \%$ formalin solution, processed using an automatic tissue processor (TP1020; Leica, Rueil Malmaison, France), and embedded in paraffin. Each pancreatic piece was cut throughout its length into $5 \mu \mathrm{m}$ thick sections, which were collected on gelatin-coated slides. The slides were left at $37^{\circ} \mathrm{C}$ overnight, then stored at $4{ }^{\circ} \mathrm{C}$ until processing for immunohistochemical studies.

\section{Immunohistochemistry and morphometry}

Every 30th section (yielding four or five sections from each pancreatic piece, eight to ten per pancreas) was immunostained for insulin. $\beta$-Cells were detected with a polyclonal guinea pig anti-insulin antibody (Dako, Trappes, France) revealed after incubation with a peroxidase anti-guinea pig antibody (Jackson Immunoresearch, Beckman Coulter, Roissy, France) and visualized in brown with 3,3'diaminobenzidine (Vector, AbCys, Paris, France). The sections were lightly counterstained thereafter. Previous experiments had shown that these conditions allowed the detection of all insulin-positive cells (Garofano et al. 1998a). Pancreatic tissue area, insulin-positive cell area, and individual $\beta$-cell areas were determined by computerassisted measurements using a Leica microscope and software, as previously described (Garofano et al. 1998a). $\beta$-Cell fraction in the pancreas was calculated as the ratio of the insulin-positive area to the total area of the tissue sections (see below). Individual $\beta$-cell areas were manually measured on the same sections in at least 50 insulinpositive cells per animal ( $n=4$ or 5 animals per group and stage of pregnancy). Proliferating $\beta$-cells were detected on the adjacent sections by fluorescence double immunohistochemistry for BrdU and insulin, using a polyclonal guinea-pig anti-insulin antibody revealed with an FITCconjugated anti-guinea pig antibody (Dako) and a monoclonal mouse anti-BrdU antibody (Amersham, Les Ulis, France) revealed with a Texas Red dye-conjugated antimouse antibody (Jackson Immunoresearch). Fluorescence was detected using a Leica DMRB microscope. $\beta$-Cell proliferation was determined in 5000-8000 insulinpositive cells per animal as the ratio of the $\beta$-cell BrdUlabelled nuclei to the total $\beta$-cell nuclei (BrdU labelling index (LI) expressed in percentage). Head and tail pancreatic regions were characterized by fluorescence double immunohistochemistry for glucagon and pancreatic polypeptide (PP), using a polyclonal rabbit anti-PP antibody (Euro-Diagnostica, AbCys, Paris, France), revealed with a Texas Red dye-conjugated anti-rabbit antibody (Jackson Immunoresearch), and a monoclonal mouse anti-glucagon antibody (Sigma), revealed with an FITC-conjugated anti-mouse antibody (Jackson Immunoresearch). Prolactin receptor (PRLR) expression in the $\beta$-cells was examined by fluorescence double immunohistochemistry for insulin and PRLR. A polyclonal rabbit anti-PRLR antibody (kindly provided by Robert L Sorenson (Brelje et al. 2002)), and a monoclonal mouse anti-insulin antibody (Sigma) were used as primary antibodies, and revealed with an FITC-conjugated antirabbit antibody and a Texas Red dye-conjugated antimouse antibody (Jackson Immunoresearch). Controls for 
immunostaining consisted of the omission of the primary antibodies, and these tests resulted in negative staining reactions.

Comparison of the morphometric data from control and PM animals was performed in two ways: separately for the head and the tail of the pancreas and also as mean values for each pancreas. Mean $\beta$-cell fraction per adult pancreas was calculated as the ratio of the sum of insulin-positive area $(($ head sections 1 to $n)+($ tail sections 1 to $n))$ to the sum of pancreatic tissue area ((head sections 1 to $n)+($ tail sections 1 to $n)$ ). Mean $\beta$-cell BrdU LI was similarly calculated.

\section{Lactogenic activity bioassay}

The lactogen-dependent $\mathrm{Nb} 2$ lymphoma cells (gift of $\mathrm{V}$ Goffin, INSERM U344, Paris, France, clone obtained from P Gout) were maintained as suspension cultures in $75 \mathrm{~cm}^{2}$ tissue culture flasks in RPMI medium supplemented with $10 \%$ horse serum and $10 \%$ fetal calf serum (FCS). Twenty-four hours before their use in the bioassay, cells were transferred to medium containing 1\% FCS, in order to slow down the rate of proliferation, and then plated in $96-w e l l$ plates $(20000$ cells $/ 200 \mu \mathrm{l}$ per well) in medium without FCS. The lactogenic activity present in plasma samples from control and malnourished females before and during pregnancy was tested in quadruplicate. Rat prolactin (NIDDK, rPRL-B7) was used as standard, in concentrations ranging from $100 \mathrm{pg} / \mathrm{ml}$ to $2 \mathrm{ng} / \mathrm{ml}$. Cells were allowed to grow up for 4 days and proliferation was measured by ELISA reaction with a WST-1 kit (Roche Molecular Biochemicals, Meylan, France). Lactogenic activity (expressed in $\mathrm{ng} / \mathrm{ml}$ ) in the female plasma samples was deduced from the proliferation measured in standard samples of known concentrations.

\section{Statistical analysis}

Data are given as means \pm S.D. The evolution of the various parameters during pregnancy for each animal group was studied using the Kruskal-Wallis test. For studying the specific regional adaptation, the parameters were compared using the Wilcoxon test, considering head and tail as paired values. Further comparisons between groups at a specific stage of pregnancy, and/or in a specific pancreatic region, were done with the Mann-Whitney test. A $P$ value $<0.05$ was considered statistically significant.

\section{Results}

\section{Adaptation of $\beta$-cell fraction to pregnancy is impaired in PM females}

In a recent study we had shown that PM females do not adapt their endocrine mass to pregnancy at 8 months of

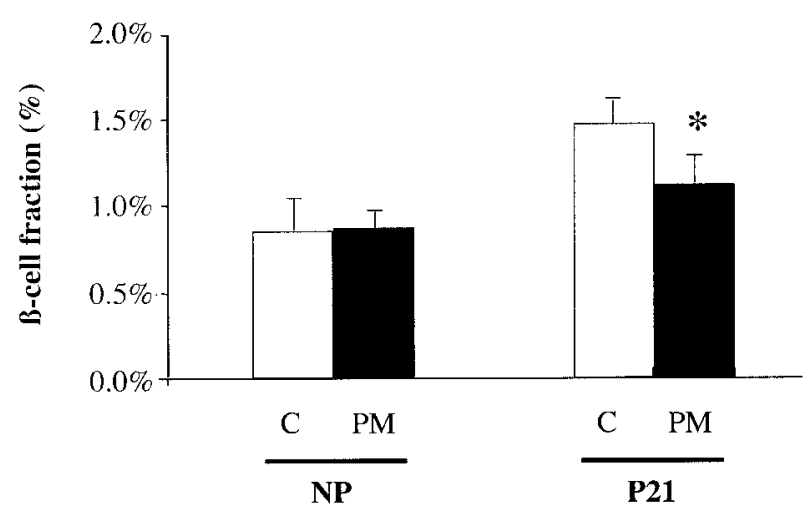

Figure 1 Adaptation of $\beta$-cell fraction to pregnancy in control (C) and previously malnourished (PM) females. $\beta$-Cell fraction was determined by morphometry (as described in Materials and Methods) in pancreases from non-pregnant (NP) females and at day 21 (P21) of pregnancy. Values are means \pm S.D. from three pancreases analysed per group and age. Values of $\beta$-cell fractions were compared using the Mann-Whitney test. ${ }^{*} P<0 \cdot 05$ PM vs $C$ at P21.

age, using morphometric measurements after dithizone staining of the pancreas (Blondeau et al. 1999). As shown in Fig. 1 , the $\beta$-cell fraction in the pancreas increases by $73 \%$ in 8 -month-old control females at day 21 of pregnancy, compared with non-pregnant values $(P<0 \cdot 05)$, whereas the increase was only moderate $(29 \%, P=0.04$ vs non-pregnant) in PM females ( $P=0.049$ vs controls). As the normal adaptation of $\beta$-cell mass to pregnancy is known to involve both $\beta$-cell hypertrophy and hyperplasia, morphometric measurements of individual $\beta$-cell size and $\beta$-cell proliferation during pregnancy were undertaken in PM and control females.

\section{Individual $\beta$-cell size during pregnancy}

Individual $\beta$-cell size measurements showed that a slight hypertrophy occurred in the $\beta$-cells during pregnancy (Fig. 2): $131.9 \pm 9 \cdot 5 \mu \mathrm{m}^{2}$ at day 21 vs $117 \cdot 7 \pm 5 \cdot 8 \mu \mathrm{m}^{2}$, non-pregnant, in PM females $(P=0 \cdot 043)$ and $136 \cdot 0 \pm$ $11.3 \mu \mathrm{m}^{2}$ at day $21 \mathrm{vs} 121.7 \pm 5.9 \mu \mathrm{m}^{2}$, non-pregnant, in controls $(P=0 \cdot 083)$. No differences were observed between control and PM females at any stage.

\section{$\beta$-Cell proliferation during pregnancy}

$\beta$-Cell proliferation rates were studied before and during pregnancy in control and PM females. In control females, $\beta$-cell BrdU LI was very low before pregnancy $(0 \cdot 07 \pm 0 \cdot 04 \%)$ but increased 17 -fold at day 12 and decreased thereafter as pregnancy progressed to reach again low levels at day 21 of pregnancy (Fig. 3). In PM females, $\beta$-cell BrdU LI was decreased compared with 

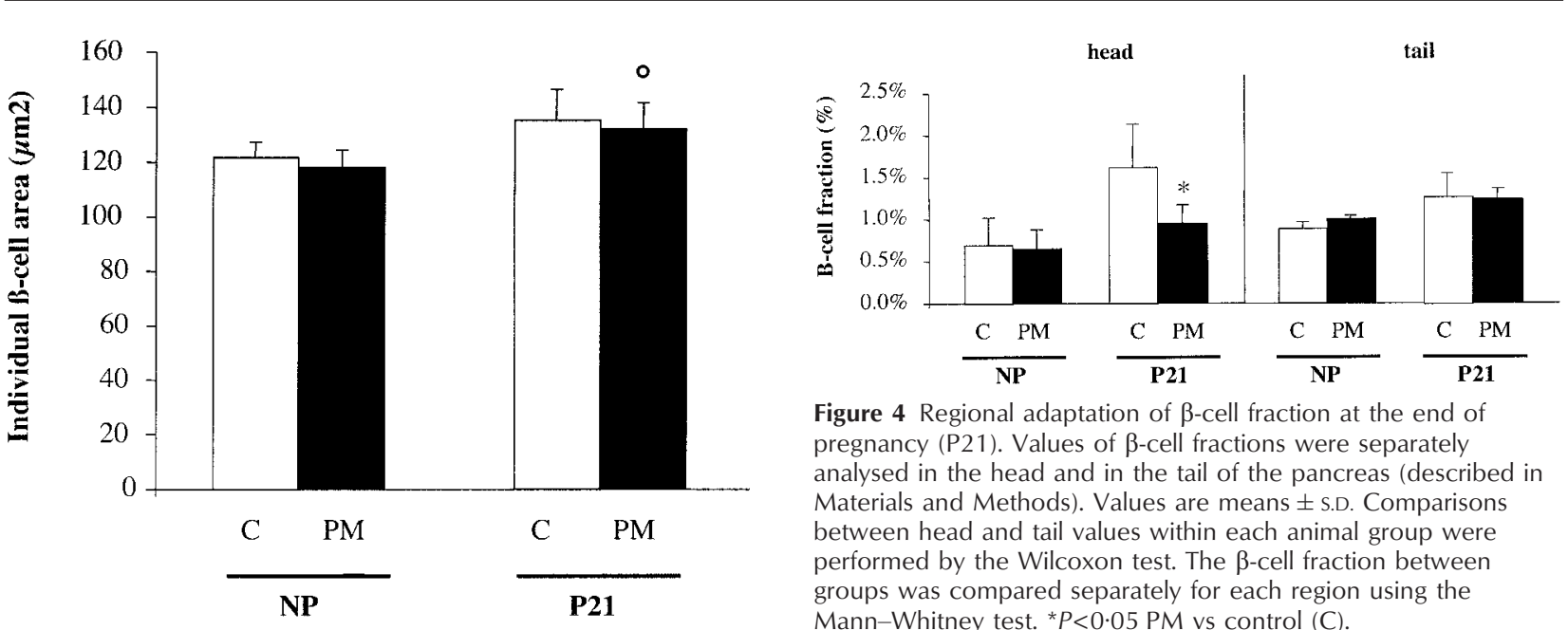

Figure 4 Regional adaptation of $\beta$-cell fraction at the end of pregnancy (P21). Values of $\beta$-cell fractions were separately analysed in the head and in the tail of the pancreas (described in Materials and Methods). Values are means \pm S.D. Comparisons between head and tail values within each animal group were performed by the Wilcoxon test. The $\beta$-cell fraction between groups was compared separately for each region using the Mann-Whitney test. ${ }^{*} P<0 \cdot 05$ PM vs control (C).

Figure 2 Individual $\beta$-cell size in control $(\mathrm{C})$ and $\mathrm{PM}$ females. $\beta$-Cell area was measured in 50 insulin-positive cells per animal. Four or five animals were studied per group, at NP stage and at $P 21$. Values are means \pm S.D. Values of $\beta$-cell area were compared using the Mann-Whitney test. ${ }^{\circ} P<0 \cdot 05$ compared with the respective NP group.

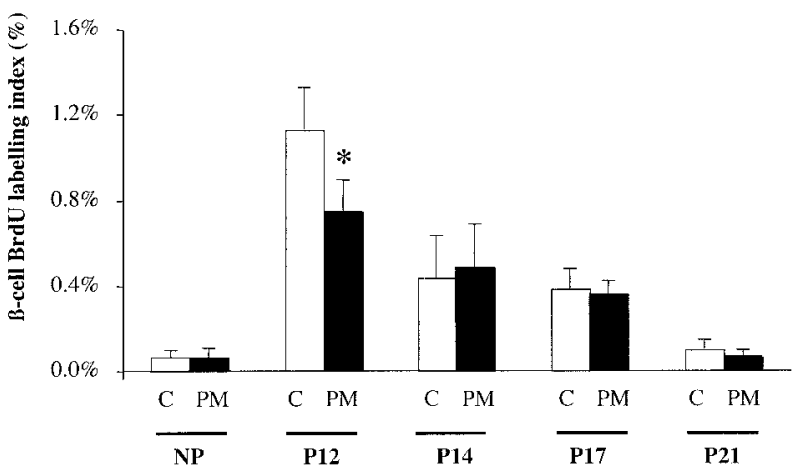

Figure $3 \beta$-Cell proliferation in control (C) and PM females throughout pregnancy. BrdU LI was determined, for each group, in pancreatic sections from NP females and at P12, P14, P17 and P21. Proliferation was determined by counting the percentage of BrdU-positive cells among 3000-4000 insulin-positive cells per animal. Values are means \pm S.D. BrdU LIs throughout pregnancy were first analysed using the Kruskal-Wallis test. Group differences at each stage of pregnancy were then compared using the Mann-Whitney test. *P<0.05 PM vs C at P12.

control values at day 12 of pregnancy $(0 \cdot 7 \pm 0 \cdot 15 \%$ in PM vs $1 \cdot 13 \pm 0 \cdot 20 \%$ in controls, $P<0 \cdot 05)$ but not at the other stages (Fig. 3).

The alteration in PM females takes place in the head of the pancreas

In order to better characterize the observed alterations in $\beta$-cell fraction and proliferation, a separate analysis was undertaken in the head and the tail of the pancreas. The head part of the pancreas is composed of PP-rich islets with fewer glucagon cells, whereas the tail corresponds to

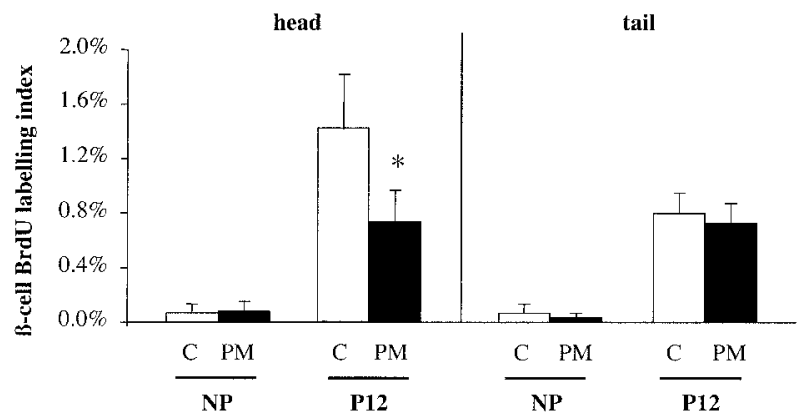

Figure 5 Regional alteration of $\beta$-cell proliferation at P12 (mid-pregnancy). $\beta$-Cell BrdU LIs were separately analysed in the head and in the tail of the pancreas (described in Materials and Methods). Values are means \pm S.D. Comparisons between head and tail values within each animal group were performed by the Wilcoxon test. $\beta$-Cell BrdU LIs were compared separately for each region using the Mann-Whitney test. ${ }^{*} P<0 \cdot 05$ PM vs control (C).

a glucagon-rich and PP-poor region (Fig. 6E and F). In control animals at day 21 of pregnancy and compared with non-pregnant values, $\beta$-cell fraction did not increase similarly in the head and in the tail but with a preferential increase in the head of the pancreas (Fig. 4). The $\beta$-cell fraction increased by $2 \cdot 3$-fold in the head and only $1 \cdot 4$-fold in the tail of the organ in control females. Interestingly, this specific regional increase in the head of the pancreas did not occur in PM females (1.4-fold vs 1.2-fold, head and tail respectively, and compared with non-pregnant values). Similarly, the separate analysis of $\beta$-cell proliferation rate in the head and the tail of the pancreas in control animals showed that the adaptation of $\beta$-cell proliferation during pregnancy mostly took place in the head of the pancreas. This regional difference was more elevated at day 12 than at the other stages of pregnancy considered together $(P=0 \cdot 07)$. In control animals at day 12, BrdU LI increased 20-fold in the head and only 10-fold in the tail (Fig. 5 and Fig. 6A and B). In PM females, this regional increase did not occur ever during pregnancy: BrdU LI at day 12 was 
HEAD
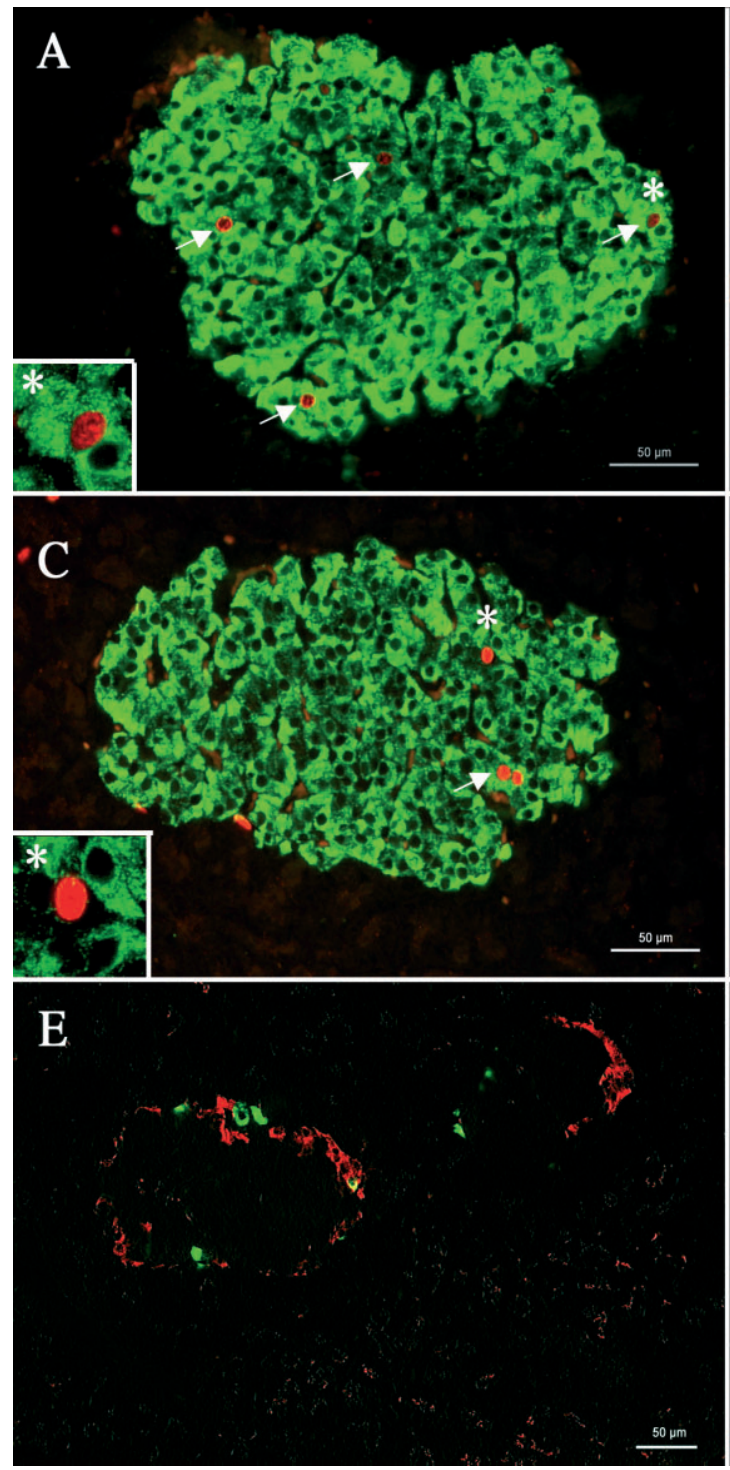

TAIL
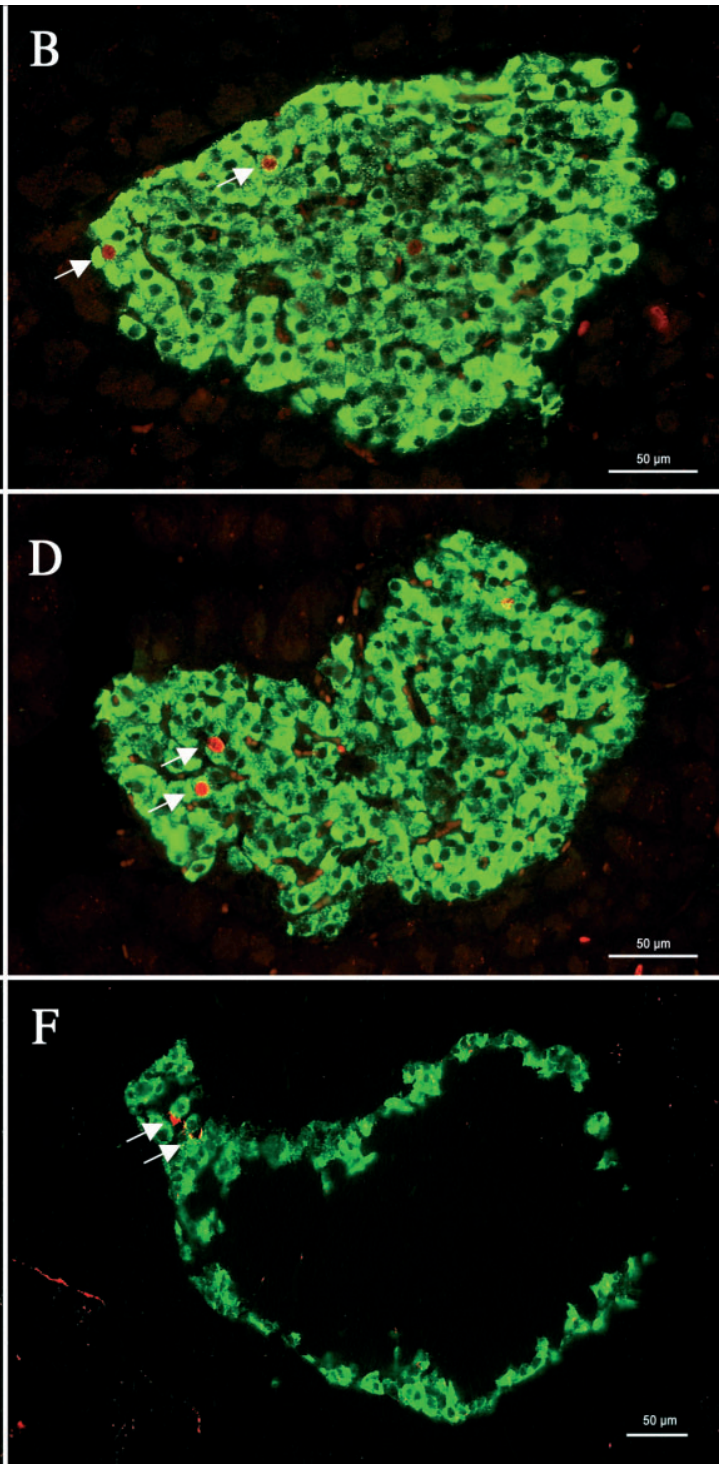

Figure $6 \beta$-Cell proliferation $(A-D)$ and endocrine cell type repartition $(E, F)$ in islets from the head or tail in control (A, B) and PM (C, D) females. (A-D) Nuclear BrdU immunostaining (red) within insulin-positive cells (green) shows $\beta$-cells in proliferation (indicated by arrows, asterisk and inset in A). Note that $\beta$-cell proliferation is decreased in the islets from the head in PM females (C) compared with controls (A). Within the islets, some cells are BrdU-positive but not insulin-positive (asterisk and inset in C). (E, F) Double immunohistochemistry for pancreatic polypeptide (PP) (red) and glucagon (green). Note in (E) that islets from the head of the pancreas are PP-rich and glucagon-poor whereas those from the tail (F) are PP-poor (red, indicated by arrows) and glucagon-rich (green).

decreased by half in the head but similar to controls in the tail, suggesting that the decreased adaptation of $\beta$-cell fraction to pregnancy in PM females was due to a decreased $\beta$-cell proliferation rate in the head of the organ.

No specific adaptation of individual $\beta$-cell size (hypertrophy) with pregnancy in the head rather than in the tail was noted in control or in PM females (data not shown).
Lactogenic activity and PRLR expression

We then investigated whether the anomalies described above in PM females were due to impaired lactogenic activity or PRLR expression. The lactogenic activity increased during pregnancy in both groups and peaked around day 12 of pregnancy (Fig. 7). At that time point the 


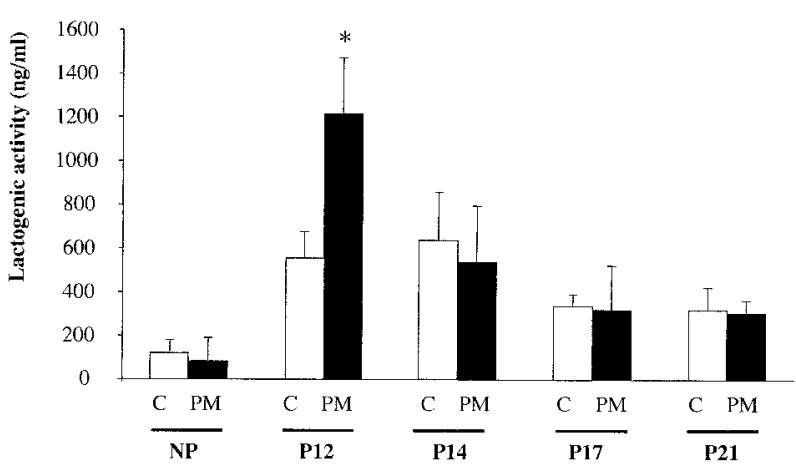

Figure 7 Lactogenic activity in control (C) and PM females throughout pregnancy. Lactogenic activity was determined on plasma samples ( $n=4$ per group and age) using the $\mathrm{Nb} 2$ cell bioassay. Values are means \pm S.D. Lactogenic activities throughout pregnancy were first analysed using the Kruskal-Wallis test. Group differences at each stage of pregnancy were then compared using the Mann-Whitney test. ${ }^{*} \mathrm{P}<0 \cdot 05 \mathrm{PM}$ vs $\mathrm{C}$ at $\mathrm{P} 12$.

values for lactogenic activity in PM females were twice those of control females $(P=0 \cdot 034)$. The presence of the PRLR was investigated by immunohistochemistry on head or tail pancreatic sections from control and PM females at day 12 of pregnancy. In the pancreatic islets the receptor was present only in $\beta$ - (insulin-positive) cells (Fig. 8). Moreover, all $\beta$-cells expressed the PRLR in both groups in the islets from the head (Fig. 8) as well as in those from the tail (data not shown).

\section{Discussion}

This work was undertaken to characterize the cellular mechanisms responsible for the absence of adaptation of the endocrine pancreas to a subsequent pregnancy, in females that had been previously malnourished during their early life. It was found that perinatal malnutrition impaired the subsequent adaptation to pregnancy by decreasing $\beta$-cell proliferation rate in the head of the pancreas at a critical time during pregnancy.

We had previously shown using dithizone staining that female rats that had been previously malnourished during their early life were unable to adapt their endocrine pancreatic mass to pregnancy (Blondeau et al. 1999). The present study confirmed this result for insulinimmunoreactive $\beta$-cells and investigated the cellular adaptive mechanisms that could be responsible for this impaired adaptation to pregnancy, namely $\beta$-cell hypotrophy and impaired proliferation. It was found that the pregnancyinduced $\beta$-cell hypertrophy was only moderate and occurred to the same extent in control and PM females. More importantly, the $\beta$-cell proliferation rate was decreased at a crucial stage at mid-pregnancy. This impairment is likely to be responsible for the lack of adaptation of the $\beta$-cell fraction observed in PM females. We also investigated whether apoptosis, a process suggested to contribute to the post-partum involution of $\beta$-cell mass (Scaglia et al. 1995) could occur in late pregnancy in PM animals and thereby contribute to the alterations. However, the very low rates of TUNELpositive nuclei $(<0 \cdot 3 \%)$ observed in both control and PM females at day 21 of pregnancy (data not shown) make this hypothesis rather unlikely.

Neogenesis has also been suggested to participate to the normal adaptation of $\beta$-cell mass to pregnancy (Aerts et al. 1997). As the contribution of this mechanism to $\beta$-cell mass increase is likely to be minor compared with the massive role of $\beta$-cell proliferation (Parsons et al. 1995) this mechanism was not investigated in the present study.

The second major finding of this study is the preferential adaptation of $\beta$-cell mass in the head rather than in the tail of the pancreas in control animals. Indeed, most of the increase in $\beta$-cell fraction at day 21 of pregnancy took place in the head of the pancreas in the normal rat, consistent with a similar preferential increase of $\beta$-cell proliferation in this region at day 12 of pregnancy. As the slight $\beta$-cell hypertrophy occurred similarly in both regions, it can be suggested that the mechanisms controlling $\beta$-cell hypertrophy and $\beta$-cell proliferation are different. This novel and interesting observation raises several comments. It is likely that the islets in the head part of the pancreas are more vascularized than those from the tail and thereby more susceptible to variations of nutrient or growth factor availability. This specific regional adaptation could also suggest that the islets from the head and the tail respond to different stimuli. Furthermore, the head part of the pancreas is composed of PP-rich islets with fewer glucagon cells, whereas the tail corresponds to a glucagonrich and PP-poor region (Orci 1982, Reddy \& Elliott 1988). To what extent this regional islet cell repartition plays a role in the preferential adaptation of $\beta$-cell mass and proliferation in the head of the pancreas remains to be determined.

The third important finding is that this specific and regional adaptation to pregnancy in the head of the pancreas is altered by previous undernutrition. This regional decrease seems to be a general consequence of undernutrition. Hence, a more pronounced alteration of the $\beta$-cell fraction in the head of the pancreas has already been observed in adult male offspring from the same animal model (Garofano et al. 1999). Additionally, in another model of undernutrition induced by feeding a low-protein diet during pregnancy, it was found that the offspring showed a decreased islet vascularization associated with a decreased islet numerical density in the head of the pancreas (Snoeck et al. 1990). It is possible that similar vascular alterations took place in the PM females from this study, thereby reducing the local nutrient and growth factor availability in the islets from the head. This hypothesis is compatible with the later development of the ventral bud from which the head of the pancreas is derived (Slack 


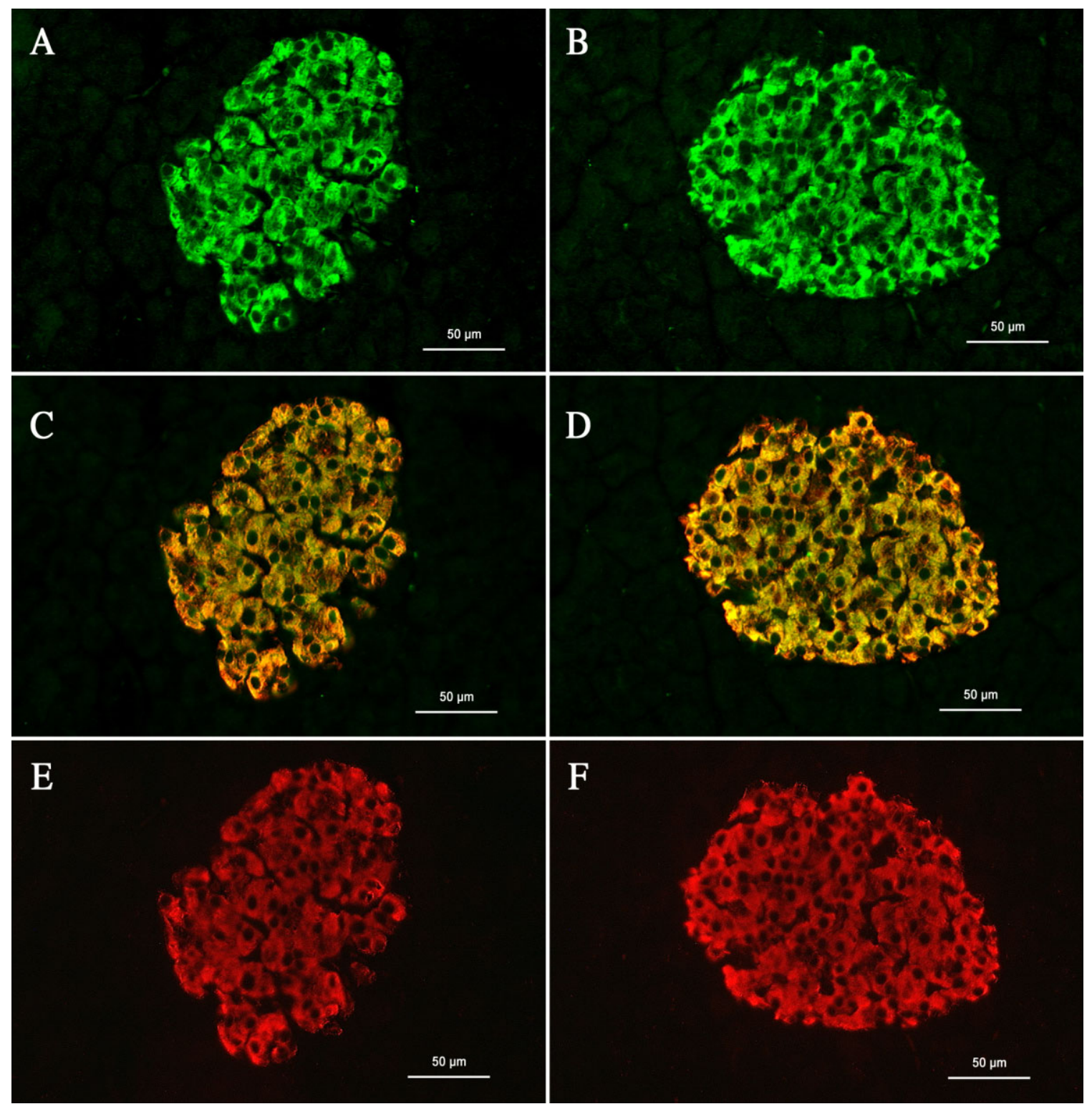

Figure 8 PRLR expression in $\beta$-cells $(C, D)$ from control $(A, C$ and $E$ ) and malnourished females $(B, D$ and $F)$ in the head part of the pancreas. Double immunohistochemistry was performed for PRLR (green, A and B) and insulin (red, E and F). Note that PRLR is expressed in all $\beta$-cells in both groups (yellow, C and D). Similar results were found in the tail part (not shown).

1995, Yamaoka \& Itakura 1999), rendering this region more susceptible to be affected by late undernutrition, such as used in this rat model.

Alternatively, this alteration observed during pregnancy could be due to specific regional modifications in growth factor availability, receptor expression or impaired signalling. In normal rats the $\beta$-cell mass increase during pregnancy is under the control of two PLs, PL I and PL II, that stimulate $\beta$-cell proliferation (Brelje et al. 1993, Kawai \& Kishi 1997, Fleenor et al. 2000, Vasavada et al. 2000).
PL $\mathrm{I}$ is the first to be secreted and peaks at day 12 of pregnancy (Parsons et al. 1992) coinciding with the alterations noted in PM females. Circulating levels of PL I normally fall as PL II levels rise at day 14 of pregnancy and remain high until the end of gestation (Parsons et al. 1992). Surprisingly, the lactogenic activity was increased in PM females at day 12 of pregnancy, in comparison with controls, whereas $\beta$-cell proliferation was decreased. These results are consistent with those obtained in another model in which the females, malnourished during pregnancy, 
also show a decreased $\beta$-cell proliferation rate associated with increased lactogenic activity (Nieuwenhuizen et al. 1999). The hypothesis that enhanced lipid concentration could be responsible for increased lactogenic activity in the present study seems unlikely, as cholesterol and triglyceride concentrations were similar in PM and control females, before and during pregnancy (data not shown).

The findings of increased lactogenic activity at day 12 of pregnancy in PM females together with a decreased final proliferation effect suggest that early undernutrition has affected the later responsiveness or sensitivity of the pancreas to lactogenic hormones. This observation is analogous to the decreased insulin sensitivity described in human adults born with IUGR (Jaquet et al. 2000). More generally, it may suggest that fetal undernutrition is altering the set point of response of tissues to hormones, another consequence of fetal programming. Although immunohistochemistry is not a quantitative process it could reliably be used to analyse the number of $\beta$-cells expressing the PRLR in the malnourished compared with control females; we found that all $\beta$-cells expressed the receptor, suggesting that the defect leading to decreased $\beta$-cell proliferation may either be due to decreased numbers of receptor molecules per $\beta$-cell or be a post-receptor defect leading to impaired signalling. This issue needs to be further investigated.

Taken together these results suggest that the further adaptation of $\beta$-cell proliferation to pregnancy could be programmed by regional alteration of islet development and hormonal tissue sensitivity due to nutritional manipulation in fetal life.

\section{Acknowledgements}

This work was funded by Institut National de la Santé et de la Recherche Médicale (INSERM). I A and B B are doctoral recipients of the Ministère de l'Education Nationale, de la Recherche et de la Technologie. The authors thank R L Sorenson for the gift of the PRL receptor antibody, $\mathrm{V}$ Goffin for providing the $\mathrm{Nb} 2$ cells and J Gallego for his help in the statistical analysis.

\section{References}

Aerts L, Vercruysse L \& Van Assche FA 1997 The endocrine pancreas in virgin and pregnant offspring of diabetic pregnant rats. Diabetes Research and Clinical Practice 38 9-19.

Blondeau B, Garofano A, Czernichow P \& Breant B 1999 Age-dependent inability of the endocrine pancreas to adapt to pregnancy: a long-term consequence of perinatal malnutrition in the rat. Endocrinology 140 4208-4213.

Bone AJ \& Taylor KW 1976 Metabolic adaptation to pregnancy shown by increased biosynthesis of insulin in islets of Langerhans isolated from pregnant rat. Nature 262 501-502.

Brelje TC, Scharp DW, Lacy PE, Ogren L, Talamantes F, Robertson M, Friesen HG \& Sorenson RL 1993 Effect of homologous placental lactogens, prolactins, and growth hormones on islet B-cell division and insulin secretion in rat, mouse, and human islets: implication for placental lactogen regulation of islet function during pregnancy. Endocrinology 132 879-887.

Brelje TC, Svensson AM, Stout LE, Bhagroo NV \& Sorenson RL 2002 An immunohistochemical approach to monitor the prolactininduced activation of the JAK2/STAT5 pathway in pancreatic islets of Langerhans. Journal of Histochemistry and Cytochemistry $\mathbf{5 0}$ 365-383.

Fleenor D, Petryk A, Driscoll P \& Freemark M 2000 Constitutive expression of placental lactogen in pancreatic beta cells: effects on cell morphology, growth, and gene expression. Pediatric Research 47 136-142.

Garofano A, Czernichow P \& Bréant B 1997 In utero undernutrition impairs rat beta-cell development. Diabetologia 40 1231-1234.

Garofano A, Czernichow P \& Bréant B 1998a Beta-cell mass and proliferation following late fetal and early postnatal malnutrition in the rat. Diabetologia 41 1114-1120.

Garofano A, Czernichow P \& Bréant B 1998 b Postnatal somatic growth and insulin contents in moderate or severe intrauterine growth retardation in the rat. Biology of the Neonate 73 89-98.

Garofano A, Czernichow P \& Bréant B 1999 Effect of ageing on beta-cell mass and function in rats malnourished during the perinatal period. Diabetologia 42 711-718.

Green IC \& Taylor KW 1972 Effects of pregnancy in the rat on the size and insulin secretory response of the islets of Langerhans. Journal of Endocrinology 54 317-325.

Jaquet D, Gaboriau A, Czernichow P \& Levy-Marchal C 2000 Insulin resistance early in adulthood in subjects born with intrauterine growth retardation. Journal of Clinical Endocrinology and Metabolism 85 1401-1406.

Kawai M \& Kishi K 1997 In vitro studies of the stimulation of insulin secretion and B-cell proliferation by rat placental lactogen-II during pregnancy in rats. Journal of Reproduction and Fertility 109 145-152.

Kawai M \& Kishi K 1999 Adaptation of pancreatic islet B-cells during the last third of pregnancy: regulation of B-cell function and proliferation by lactogenic hormones in rats. European Journal of Endocrinology 141 419-425.

Marynissen G, Aerts L \& Van Assche FA 1983 The endocrine pancreas during pregnancy and lactation in the rat. Journal of Developmental Physiology 5 373-381.

Nieuwenhuizen AG, Schuiling GA, Moes H \& Koiter TR 1997 Role of increased insulin demand in the adaptation of the endocrine pancreas to pregnancy. Acta Physiologica Scandinavica 159 303-312.

Nieuwenhuizen AG, Schuiling GA, Seijsener AFJ, Moens K \& Koiter TR 1999 Effects of food restriction on glucose tolerance, insulin secretion, and islet-cell proliferation in pregnant rats. Physiology and Behavior 65 671-677.

Orci L 1982 Macro- and micro-domains in the endocrine pancreas. Diabetes 31 538-565.

Parsons JA, Brelje TC \& Sorenson RL 1992 Adaptation of islets of Langerhans to pregnancy: increased islet cell proliferation and insulin secretion correlates with the onset of placental lactogen secretion. Endocrinology 130 1459-1466.

Parsons JA, Bartke A \& Sorenson RL 1995 Number and size of islets of Langerhans in pregnant, human growth hormone-expressing transgenic, and pituitary dwarf mice: effect of lactogenic hormones. Endocrinology 136 2013-2021.

Reddy S \& Elliott RB 1988 Ontogenic development of peptide hormones in the mammalian fetal pancreas. Experientia 44 1-9.

Scaglia L, Smith FE \& Bonner-Weir S 1995 Apoptosis contributes to the involution of beta cell mass in the post partum rat pancreas. Endocrinology 136 5461-5468.

Sheridan JD, Anaya PA, Parsons JA \& Sorenson RL 1988 Increased dye coupling in pancreatic islets from rats in late-term pregnancy. Diabetes 37 908-911.

Slack JM 1995 Developmental biology of the pancreas. Development 121 1569-1580. 
Snoeck A, Remacle C, Reusens B \& Hoet JJ 1990 Effect of a low protein diet during pregnancy on the fetal rat endocrine pancreas. Biology of the Neonate 57 107-118.

Van Assche FA, Aerts L \& Gepts W 1979 Morphological changes in the endocrine pancreas in pregnant rats with experimental diabetes. Journal of Endocrinology 80 175-179.

Vasavada RC, Garcia-Ocana A, Zawalich WS, Sorenson RL, Dann P, Syed M, Ogren L, Talamantes F \& Stewart AF 2000 Targeted expression of placental lactogen in the beta cells of transgenic mice results in beta cell proliferation, islet mass augmentation, and hypoglycemia. Journal of Biological Chemistry 275 15399-15406.
Weinhaus AJ, Stout LE \& Sorenson RL 1996 Glucokinase, hexokinase, glucose transporter 2, and glucose metabolism in islets during pregnancy and prolactin-treated islets in vitro: mechanisms for long term up-regulation of islets. Endocrinology 137 1640-1649.

Yamaoka T \& Itakura M 1999 Development of pancreatic islets (review). International Journal of Molecular Medicine 3 247-261.

Received 11 February 2002

Accepted 19 April 2002 